\title{
GREEN SYNTHESIS OF METALLIC NANOPARTICLES, PHYTOCHEMICAL COMPOUNDS AND ANTIOXIDANT ACTIVITY USING TWO TYPES OF ALGAE PLANTS
}

\author{
Ioana Raluca SUICA-BUNGHEZ ${ }^{1}$, Ileana Cristina COVALIU ${ }^{2}$, \\ Ana Alexandra SORESCU ${ }^{1,3}$, Rodica Mariana ION ${ }^{1,3}$ \\ ${ }^{1}$ The National Institute for Research \& Development in Chemistry and Petrochemistry, Romania \\ ${ }^{2}$ Faculty of Biotechnical Systems Engineering, University Politehnica of Bucharest, Romania \\ ${ }^{3}$ University Valahia of Targoviste, Romania \\ e-mail: cristina_covaliu@yahoo.com, alexiasorescu@yahoo.com
}

\begin{abstract}
Scientific studies have demonstrated that the vegetable material extracts act as potential precursors for the synthesis of nanomaterial using eco-friendly ways. Because the plant extracts contain various secondary metabolites, they act as reducing and stabilizing agents for the bioreduction reaction for synthesis of novel metallic nanoparticles.

Herein, we describe the characteristics of different algae types, from different locations (Belgium and South Correa). Algae have important components, like chlorophyll and other plant pigments, omega-3 fatty acids and essential elements. Also, it has been demonstrated that algae provide a rich source of natural bioactive compounds with antibacterial and antioxidant properties. Another important aspect is the fact that algae represent a good wastewater treatment. In addition to the economic aspect, algae biomass is a source of biodiesel and offers an efficient way for nutrient consumption and provides aerobic bacteria with oxygen through photosynthesis. It is a low-cost technique for the removal of phosphorus, nitrogen and pathogens. We first characterized and compared quantitatively (polyphenols, flavonoids) and qualitatively (carbohydrates, alkaloids) the properties of two algae types extracts (green algae - Enteromorpha spp. and brown ones - Hizikia fusiforme). We then obtained and characterized the gold nanoparticles, formed using $\mathrm{HAuCl}_{4}\left(10^{-3} \mathrm{M}\right)$ and algae sample extracts. The algae extracts, the green method for obtaining metallic nanoparticles (AuNP) and the nanoparticles investigated by UV-Vis spectroscopy, optical microscopy and SEM technique are shown in this research.
\end{abstract}

KEYWORDS: marine algae, phytochemical properties, metallic nanoparticles, green chemistry

\section{Introduction}

Nanotechnology is a rapidly growing area of science with tremendous impact in critical aspects of society, such as health and energy, with immediately applicability of metal nanoparticles in many areas such as medicine, catalysis, or electronics [1, 2]. This branch of science refers to the fabrication of nanoparticles with various shapes, sizes and their associated chemical and physical parameters for the beneficial use in material sciences, such as solar energy conversion, catalysis, microelectronics, photonics, antimicrobial functionalities and water management [3].

It has been previously demonstrated that plants, fruits, or vegetable materials (algae, fungi, bacteria) are excellent sources of compounds suitable for the obtaining of metallic (platinum, silver and gold) nanoparticles [4]. Some of these substances (polysaccharides, phenols, flavonoids, or tannins) can serve as reducing and also stabilizing agents. The bioorganic molecules from these extracts provide the opportunity of complex combinations of reducing and stabilizing agents, giving thereby rise to a large variety of parameters in the green preparation 
process, with the end result of metallic nanoparticles of different sizes and shapes [5].

Numerous attempts have been made to uncover the roles that organisms present in the accumulation of gold and its conversion to non-toxic nanoparticles [6]. Nair \& Pradeep [7] have demonstrated the production of gold and silver alloy nanoparticles using lactic acid bacteria exposed to gold and silver ion mixtures. Other groups [8,9] observed that $\mathrm{Au}$ (III) ions can be reduced to $\mathrm{Au}(0)$ by alfalfa plants or oat (Avena sativa) biomass forming Au nanoparticles. Similar nanogold synthesis has been reported in algae, including Chlorella vulgaris [10], Sargassum wightii [11] and Plectonema boryanum [12, 13]. Cyanobacteria (such as Lyngbya majuscula and Spirulina subsalsa), green algae (Rhizoclonium hieroglyphicum and $R$. riparium) and diatoms (Nitzschia obtusa and Navicula minima) has recently been reported to demonstrate potential of gold nanoparticle synthesis by Chakraborty et al. [14], and biosynthesis of gold nanorods by Nostoc ellipsosporum [15].

Over the last years, the entire process of intracellular formation of gold nanoparticles by algal biomass wasn't yet fully understood but scientists tried to demonstrate the roles that microorganisms, marine algae plants can play in the capturing of gold and its conversion to non-toxic nanoparticles, using ecofriendly methods [16].

Marine algae have received increased importance as a source for the synthesis of nanoparticles. Bioactive metabolites isolated from seaweed algae such as flavonoids, citric or ascorbic acid, polyphenolics, terpenes, alkaloids and reductase could act as reducing agents [17]. Previous studies

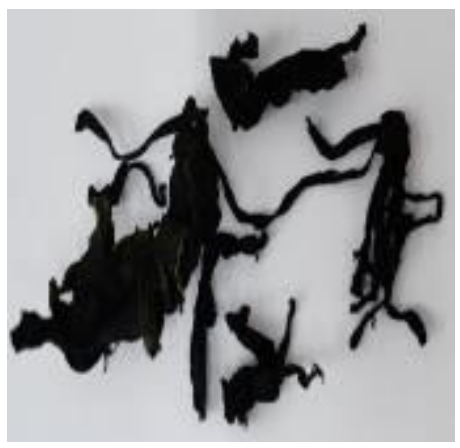

a) propose that there are certain marine algae suitable not for only for gold nanoparticles synthesis, even for silver [18] or platinum [19] nanoparticles. Another studies, using Galaxaura elongata [20] or Gelidiella acerosa [21], showed for the first time the synthesis of highly stable Ag-NPs with its antimicrobial activity. Also, research studies were performed on $G$. acerosa marine algae, with demonstrated rich antioxidant characteristics, anticancer activity, cytotoxicity and antibacterial activity [22].

The use of biological processes for the treatment of wastewaters metal pollution can overcome the barriers of physical and chemical treatments and provide a way for a low-cost removal of metals. Therefore, a big interest has been generated using different types of inexpensive biomass for adsorbing or removing the heavy metals $(\mathrm{Cr}, \mathrm{Ni}, \mathrm{Cu}, \mathrm{Cd}, \mathrm{Fe}$, etc) from wastewater [23]. It is very important to appreciate and appreciate the importance of seaweeds in this moment, when earth can no longer sustain the lot of wastes [24].

\section{Materials and methods}

We used different algae types, from Belgium and South Correa (Fig. $1 \mathrm{a}$ ) and b). The dried marine algae were green (Enteromorpha spp.) and brown (Hizikia fusiforme). $0.5 \mathrm{~g}$ from each dried algae were extracted in a hydroalcoholic mixture (EtOH: $\mathrm{H}_{2} \mathrm{O}$ distilled), using ultrasound bath (1 hour). Then, the solutions were macerated at room temperature, in the dark, for 48 hours. The extracts were filtered through a filter paper to obtain clear samples.

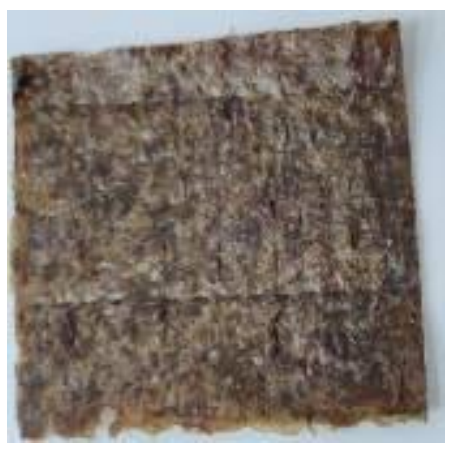

b)

Fig. 1. a) AB-Belgium algae (Enteromorpha spp) and b) AC-South Correa algae (Hizikia fusiforme) dried plants

It is noteworthy to specify that the algae were chosen to obtain metallic nanoparticles, after we observed positive results for total phytochemical contents and antioxidant activity, with a high potential in balancing the oxidative stress.
For determinations of phytochemical methods, $\mathrm{NaNO}_{2}, \mathrm{NaOH}, \mathrm{Na}_{2} \mathrm{CO}_{3}, \mathrm{DPPH}$ and Folin-Ciocalteu reagent, from Merck and $\mathrm{AlCl}_{3}$, Benedict and Millon reagents from Sigma-Aldrich were used. For gold 
nanoparticles, $\mathrm{HAuCl}_{4}$ was purchased from Acros Organics.

Preparation of gold nanoparticles (AuNP) formed in the presence of hydro-alcoholic extracts 5 $\mathrm{mL}$ of fruit extract sample were added to $5 \mathrm{~mL}$ $\mathrm{HAuCl}_{4}\left(10^{-3} \mathrm{M}\right)$, ultrasonicated on Bioblock
Scientific $\left(30 \mathrm{~min} / 40{ }^{\circ} \mathrm{C}\right.$ ) ultrasound bath, then kept in the dark overnight, at room temperature.

All experimental measurements were carried out in triplicate and are expressed as average of three analyses. Total flavonoids and polyphenols content were calculated utilizing the results of curve calibration standards (Table 1).

Table 1. Preparation methods of phytochemicals analyses

\begin{tabular}{|c|c|c|c|c|c|}
\hline No. & Assay & Reagents & Conditions & $\begin{array}{l}\text { Monitoring and } \\
\text { calibration }\end{array}$ & References \\
\hline 1 & $\begin{array}{c}\text { Total } \\
\text { Flavonoids } \\
\text { Content }\end{array}$ & $\begin{array}{c}1 \mathrm{~mL} \text { extract }+4 \mathrm{~mL} \\
\text { distilled water }+0.3 \mathrm{~mL} \\
\mathrm{NaNO}_{2}(5 \%) \text {; After } 5 \mathrm{~min} \text { : } \\
0.3 \mathrm{~mL} \mathrm{AlCl}_{3}(10 \%) \text {; After } \\
5 \mathrm{~min}: 2 \mathrm{~mL} 1 \mathrm{M} \mathrm{NaOH}+ \\
2.4 \mathrm{~mL} \text { distilled water }\end{array}$ & $\begin{array}{l}30 \text { minutes } \\
\text { kept at room } \\
\text { temp. }\end{array}$ & $\begin{array}{l}\text { Absorbance at } 510 \\
\mathrm{~nm} \text {; Catechin curve } \\
\text { calibration standard } \\
\quad\left(\mathrm{R}^{2}=0.9988\right)\end{array}$ & 25,26 \\
\hline 2 & $\begin{array}{c}\text { Total } \\
\text { Polyphenols } \\
\text { Content }\end{array}$ & $\begin{array}{c}1 \mathrm{~mL} \text { diluted extract }+5 \\
\mathrm{~mL} \text { Folin-Ciocalteu } \\
\text { reagent. } \\
\text { After } 8 \text { min: } 4 \mathrm{~mL} \mathrm{Na} \mathrm{CO}_{3}\end{array}$ & $\begin{array}{l}60 \text { min kept } \\
\text { at room temp }\end{array}$ & $\begin{array}{c}\text { Absorbance at } 765 \\
\mathrm{~nm} \text {; Gallic acid curve } \\
\text { calibration standard } \\
\left(\mathrm{R}^{2}=0.9944\right)\end{array}$ & 27,28 \\
\hline
\end{tabular}

Absorption spectroscopy. The absorption spectra of the sample extracts and of the samples with silver nanoparticles were obtained using an Analytic Jena UV-VIS spectrophotometer, in the wavelength range of $250-750 \mathrm{~nm}$.

Optical microscopy. The optical microscopy was performed with a Novex trinocular microscope (EUROMEX Microscopen B.V. HOLLAND) (at different magnifications: $40 \times, 10 \times, 400 \times, 100 \times)$.

Scanning Electron Microscopy (SEM). It was used the Scanning Electron Microscope (SEM) SU70 (Hitachi, Japan), very sensitive equipment, with field emission which is based on a Schottky electron source. The application field of SEM (coupled with EDS, WDS and EBL) was utilized for characterization of micro- and nanoparticles from samples.

Antioxidant activity determination. The antioxidant activity of the extracts was evaluated using the DPPH method [25], via spectrophotometry. The algae samples were evaluated at $100 \mathrm{mg} / \mathrm{L}$ concentration, by mixing $0.5 \mathrm{~mL}$ of extract with $1 \mathrm{~mL}$ of DPPH solution $(2 \mathrm{mg} / 100 \mathrm{~mL})$. The samples were mixed 30 minutes and kept in the dark for 30 minutes, at room temperature. After that, each mixture sample was tested for the DPPH radical-scavenging activity by measuring the absorbance at $517 \mathrm{~nm}$ on a UV-VIS spectrophotometer. The antioxidant activity (AA \%) was calculated using the formula:

$$
\mathrm{AA} \%=\left[\left(\mathrm{A}_{\text {Control }}-\mathrm{A}_{\text {Extract }}\right) / \mathrm{A}_{\text {Control }}\right] \times 100
$$

where: AControl is the absorbance of a DPPH solution without extract, AExtract is the absorbance of the sample extract with DPPH $(2 \mathrm{mg} / 100 \mathrm{~mL})$.

\section{Results and discussion}

Results of phytochemicals content are presented in Table 2 .

The qualitative tests presented in table 3 and 4 confirmed that both algae have carbohydrates and alkaloids in their structure.

Table 2. Results of phytochemicals content for algae plants

\begin{tabular}{|c|c|c|c|}
\hline Algae extract & $\begin{array}{c}\text { Antioxidant } \\
\text { activity } \\
\text { AA \% }\end{array}$ & $\begin{array}{c}\text { Total flavonoid } \\
\text { content } \\
\text { TFC mg/L }\end{array}$ & $\begin{array}{c}\text { Total polyphenols } \\
\text { content } \\
\text { TPC mg/L }\end{array}$ \\
\hline AB (Enteromorpha spp.) & 85.395 & 342.56 & 97.178 \\
\hline AC (Hizikia fusiforme) & 79.728 & 182.23 & 52.262 \\
\hline
\end{tabular}


THE ANNALS OF “DUNAREA DE JOS” UNIVERSITY OF GALATI

FASCICLE IX. METALLURGY AND MATERIALS SCIENCE

No. 1 - 2021, ISSN 2668-4748; e-ISSN 2668-4756

Article DOI: $\underline{\text { https://doi.org/10.35219/mms.2021.1.06 }}$

Table 3. Results of qualitative tests for carbohydrates

\begin{tabular}{|c|c|c|}
\hline \multirow{2}{*}{ Reagent/test } & \multicolumn{2}{|c|}{ Algae extract } \\
\hline & AB (Enteromorpha spp.) & AC (Hizikia fusiforme) \\
\hline Molish reagent & + & + \\
\hline Benedict reagent & + & + \\
\hline Fehling B reagent & + & + \\
\hline Ammonium molybdite test & + & + \\
\hline $\mathrm{CoCl}_{2}$ test & + & + \\
\hline Seliwanoff reagent & + & + \\
\hline Barfoed reagent & + & + \\
\hline
\end{tabular}

Table 4. Results of qualitative tests for alkaloids

\begin{tabular}{|c|c|c|c|}
\hline Algae extract & Mayer reagent & Wagner reagent & Hager reagent \\
\hline $\mathrm{AB}$ (Enteromorpha spp.) & + & + & + \\
\hline $\mathrm{AC}$ (Hizikia fusiforme) & + & + & + \\
\hline
\end{tabular}

Characterization of metallic nanoparticles formed in presence of algae extract samples. The metallic nanoparticles samples were obtained by mixing of $5 \mathrm{~mL}$ from hydroalcoholic algae extract with $5 \mathrm{~mL}$ of aqueous solution of $10^{-3} \mathrm{M}, \mathrm{HAuCl}_{4}$; then the samples were ultrasonicated and were kept

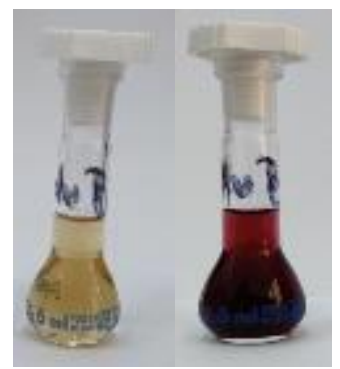

a) overnight at room temperature. Visually, the formation of nanoparticles was evidenced by changes of color of mixed solutions (Fig. 2), due to excitation of surface plasmon vibrations in the metal nanoparticles.

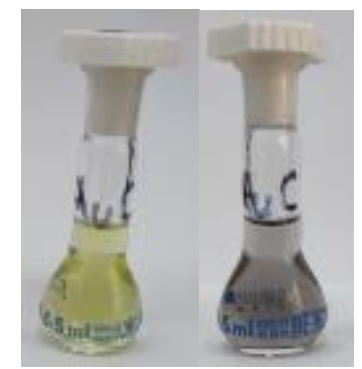

b)

Fig. 2. Color changed after 4 and 24 hours of A) $A u N P-A B$ and B) AuNP-AC solutions

$U V$-VIS results. The absorption bands between 280-360 $\mathrm{nm}$ wavelengths of algae extract samples presented specific peaks of phenolic acids and flavonoids [26], while the UV-VIS absorption spectrum of algae extract-AuNP samples (Fig. 3b) was observed between 540-580 nm areas for AuNP. The peaks appeared between $430-457 \mathrm{~nm}$ and 645$660 \mathrm{~nm}$, in both algae extract samples are attributed to chlorophyll a and b [29].
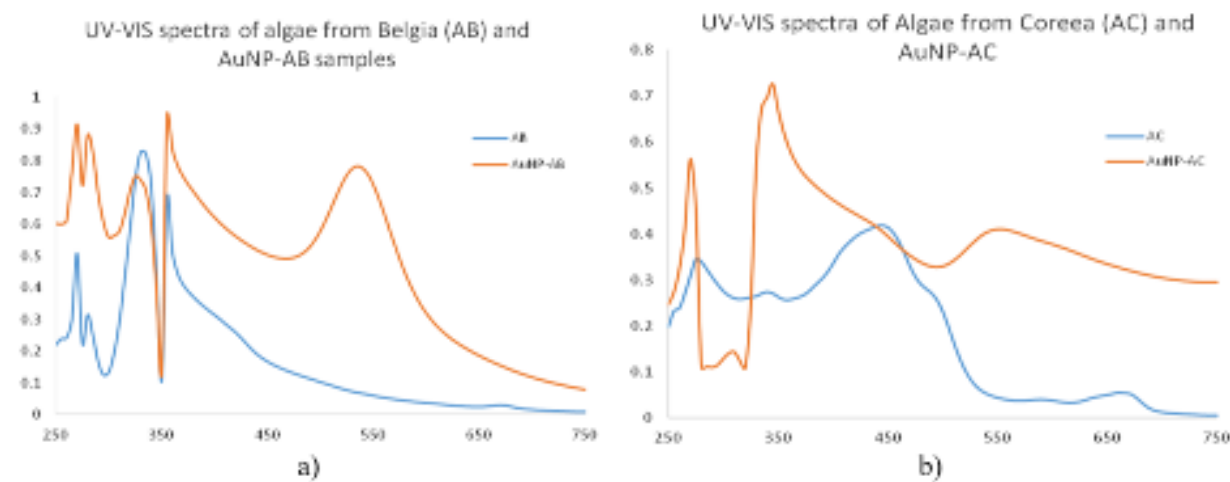

Fig. 3. UV-Vis spectra of algae extract and gold nanoparticles (AuNP) 
Antioxidant activity of AuNP-algae extract samples is presented in Table 5 .

Table 5. Results of qualitative tests for alkaloids

\begin{tabular}{|c|c|}
\hline Sample name & AA \% \\
\hline AB (Enteromorpha spp.) & 91.096 \\
\hline AC (Hizikia fusiforme) & 87.154 \\
\hline
\end{tabular}



a)

Fig. 4. Optical microscopy of AC (Enteromorpha spp.) dried algae and AC-AuNP sample

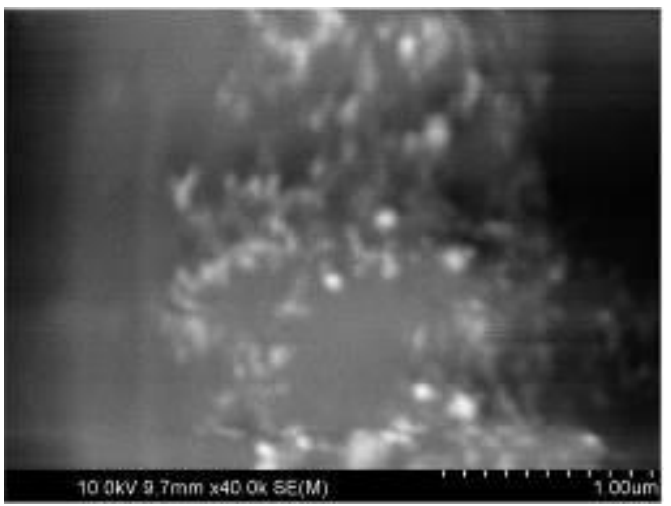

Fig. 5. SEM of gold nanoparticles of Hizikia fusiforme

\section{Conclusions}

In the present study we report a simple, economical and eco-friendly bottom-up approach to design gold nanoparticles using two different types of dried algae: green algae (Enteromorpha spp.) and brown ones (Hizikia fusiforme) and $\mathrm{HAuCl}_{4}\left(10^{-3} \mathrm{M}\right)$, which determined a shift in the color of the extracts. This was demonstrated using UV-Vis spectroscopy, which showed specific wavelengths for gold nanoparticles AuNP, between 500-550 nm. Using SEM technology, we characterized the obtained gold nanoparticles, with measurements of the average size of the synthesized nanoparticles between 10-50 nm, with spherical in morphology and capped by phytochemicals. Also, optical microscopy allowed us
In the next figure (Fig. 4), optical microscopy images of AC (Enteromorpha spp.) dried algae and the changes of algae structure after it were formed gold nanoparticles are presented.

We used scanning electron microscopy of AuNPs-Hizikia fusiforme extract to characterize the particle shape and morphology. The SEM results revealed that the gold nanoparticles possessed spherical shape with average particle size between 10-50 nm (Fig. 5).

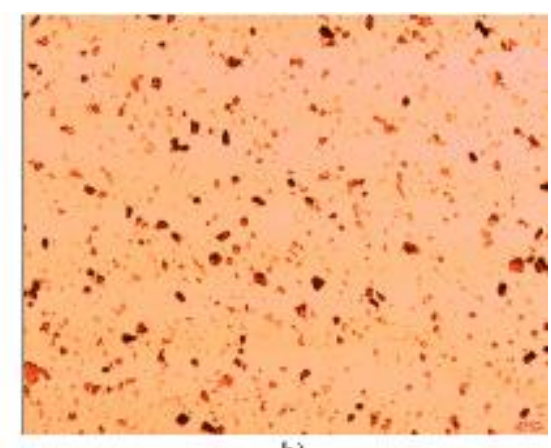

b) to see a structural parallel arrangement of dried algae structure plant. We measured the flavonoids and polyphenols contents in the obtained compounds and observed that they are higher in the green algae than the brown ones. Moreover, the high values for the measured antioxidant activity suggest a strong scavenging capacity for the gold nanoparticles samples.

Our current research concludes that the hydroalcoholic extract of algae plants possess a strong reduction efficacy of gold cations to gold nanoparticles. Due to the eco-friendly, low-cost method and the rapid capacity of algae to form nanoparticles, next step will be to make silver nanoparticles in the presence of marine algae plants and corroborated with gold nanoparticles to use them for wastewater treatment.

\section{References}

[1]. Mobasser S., Firoozi A., Review of Nanotechnology Applications in Science and Engineering, 6, 4, p. 84-93, 2017.

[2]. Kulkarni N., Uday Muddapur, Biosynthesis of Metal Nanoparticles: A Review, Journal of Nanotechnology, p. 1-8, 2014. [3]. Thomas J. Joseph Prakash, Sowmiya K., A review on nanotechnology and plant mediated metal nanoparticles and its applications, 8, 6, 20 pp, 2020.

[4]. Kuppusamy P., et al., Biosynthesis of metallic nanoparticles using plant derivatives and their new avenues in pharmacological applications - An updated report, Saudi Pharmaceutical Journal: SPJ 24, p. 473-484, 2016.

[5]. Palanco Marta Espina et al., Templated green synthesis of plasmonic silver nanoparticles in onion epidermal cells suitable for surface-enhanced Raman and hyper-Raman scattering, Beilstein Journal of Nanotechnology 7, p. 834-840, 2016. 


\section{THE ANNALS OF "DUNAREA DE JOS” UNIVERSITY OF GALATI \\ FASCICLE IX. METALLURGY AND MATERIALS SCIENCE \\ $N^{\circ} .1$ - 2021, ISSN 2668-4748; e-ISSN 2668-4756 \\ Article DOI: https://doi.org/10.35219/mms.2021.1.06}

[6]. Mehta S. K., Gaur J., Use of algae for removing heavy metal ions from Wastewater: Progress and Prospects, Critical Reviews in Biotechnology 25, p. 113-152, 2005.

[7]. Nair B., Pradeep T., Coalescence of Nanoclusters and Formation of Submicron Crystallites Assisted by Lactobacillus Strains, Crystal Growth \& Design 2, p. 293-298, 2002.

[8]. Gardea-Torresdey J. et al., Formation and Growth of Au Nanoparticles inside Live Alfalfa Plants, Nano Letters 2, p. 397401, 2002.

[9]. Armendariz V. et al., The extraction of gold nanoparticles from oat and wheat biomasses using sodium citrate and cetyltrimethylammonium bromide, studied by $x$-ray absorption spectroscopy, high-resolution transmission electron microscopy, and $U V$-visible spectroscopy, Nanotechnology 20, 10, 105607, 2009.

[10]. Ting Y. et al., Gold uptake by Chlorella vulgaris, Journal of Applied Phycology 7, p. 97-100, 2004.

[11]. Singaravelu G. et al., A novel extracellular synthesis of monodisperse gold nanoparticles using marine alga, Sargassum wightii Greville, Colloids and surfaces. B, Biointerfaces 57, 1, p. 97-101, 2007.

[12]. Lengke M. et al., Morphology of gold nanoparticles synthesized by filamentous cyanobacteria from gold(I)-thiosulfate and gold(III)--chloride complexes, Langmuir: the ACS journal of surfaces and colloids 22, 6, 2780-7, 2006.

[13]. Lengke M. et al., Mechanisms of gold bioaccumulation by filamentous cyanobacteria from gold(III)-chloride complex, Environmental science \& technology 40, 20, 6304-9, 2006.

[14]. Chakraborty N. et al., Biorecovery of gold using cyanobacteria and an eukaryotic alga with special reference to nanogold formation - a novel phenomenon, Journal of Applied, Phycology 21, p. 145-152, 2009.

[15]. Parial D. et al., Gold nanorod production by cyanobacteriaa green chemistry approach, Journal of Applied Phycology 24, p. 55-60, 2012.

[16]. Parial D. et al., Screening of different algae for green synthesis of gold nanoparticles, European Journal of Phycology 47, p. 22-29, 2012.

[17]. Santhoshkumar J., Rajeshkumar S., Kumar S. V., Phytoassisted synthesis, characterization and applications of gold nanoparticles-a review, Biochem Biophy 11, p. 46-57, 2017.
[18]. Deepak P. et. al., Structural characterization and evaluation of mosquito-larvicidal property of silver nanoparticles synthesized from the seaweed, Turbinaria ornata (Turner) J. Agardh 1848, Artif. Cells Nanomed Biotech 45, 5, p. 990-998, 2017.

[19]. Ramkumar V. S. et. al., Synthesis of platinum nanoparticles using seaweed Padina gymnospora and their catalytic activity as PVP/PtNPs nanocomposite towards biological applications, Biomed Pharmacother 92, p. 479-490, 2017.

[20]. Abdel-Raouf N. et al., Green biosynthesis of gold nanoparticles using Galaxaura elongata and characterization of their antibacterial activity, Arabian Journal of Chemistry 10, 2, S3029-S3039, 2017.

[21]. Senthil Kumar P. et al., Evaluation of alpha-amylase and alpha-glucosidase inhibitory properties of selected seaweeds from Gulf of Mannar, Int Res J Pharma 3, p. 128-130, 2011.

[22]. Senthilkumar P. et al., Facile green synthesis of gold nanoparticles from marine algae Gelidiella acerosa and evaluation of its biological Potential, SN Applied Sciences 1, p. 1-12, 2019.

[23]. Mehta S. K., Gaur J. P., Use of Algae for Removing Heavy Metal Ions From Wastewater: Progress and Prospects, Critical Reviews in Biotechnology, 25, p. 113-152, 2005.

[24]. Arumugam N. et al., Treatment of Wastewater Using Seaweed: A Review, Int. J. Environ. Res. Public Health 15, 2851, 19 p, 2018.

[25]. Şuică-Bunghez I. R. et al., Antioxidant activity and phytochemical compounds of snake fruit (Salacca Zalacca), IOP Conf. Series: Materials Science and Engineering, 133, 2016.

[26]. Şuică-Bunghez, Ioana-Raluca et al., Characterization of antioxidant activity and phytochemical compounds, metal nanoparticles obtained by Sideritis Scardica extracts", Rev. Roum. Chim., 62, 6-7, p. 545-552, 2017.

[27]. Sulaiman C. T., Balachandran I., Total Phenolics and Total Flavonoids in Selected Indian Medicinal Plants, Indian Journal of Pharmaceutical Sciences, 258:260, 2012.

[28]. ***, International Standard ISO 14502-1:2005, Determination of substances characteristic of green and black tea - Part 1: Content of total polyphenols in tea - Colorimetric method using Folin-Ciocalteu reagent.

[29]. Makarska-Bialokoz M., Kaczor A., Computational Analysis of Chlorophyll Structure and UV-Vis Spectra: A Student Research Project on the Spectroscopy of Natural Complexes, Spectroscopy Letters, 47, p. 147-152, 2014. 